\title{
Correlation between concrete-to-concrete bond strength and the roughness of the substrate surface
}

\author{
Pedro M.D. Santos ${ }^{a}$, Eduardo N.B.S. Júlio ${ }^{b, *}$, Vítor D. Silva ${ }^{b}$ \\ a Department of Civil Engineering, Polytechnic Institute of Castelo Branco, Portugal \\ ${ }^{\mathrm{b}}$ Department of Civil Engineering, Faculty of Sciences and Technology, University of Coimbra, Portugal
}

Received 2 June 2005; received in revised form 2 February 2006; accepted 31 May 2006

Available online 25 September 2006

\begin{abstract}
Previous studies proved that the bond strength between two concrete layers is highly influenced by the roughness of the substrate surface. In this paper, the authors describe a subsequent study, conducted to investigate the possibility of quantifying the roughness of the substrate surface and correlate this with the corresponding interface bond strength. Specimens with the substrate surface prepared with different roughening techniques were considered. The roughness profile of the substrate surface was obtained with digital image processing. Several roughness parameters were assessed based on this profile and were correlated with the corresponding bond strength, both in shear and in tension, measured with slant shear and pull-off tests, respectively.
\end{abstract}

(c) 2006 Elsevier Ltd. All rights reserved.

Keywords: Concrete; Roughness; Bond; Strength; Digital image

\section{Introduction}

Some strengthening techniques of concrete structures frequently involve adding new concrete to an existing concrete element. Even when the concrete substrate is not damaged, it is usual to increase the roughness of its surface with the purpose of improving the bond between both materials. Surface treatments like wire-brushing, sandblasting, water jetting, chipping, etc., are usually adopted. Júlio et al. [1] proved that the use of sand-blasting is preferred when compared with wire-brushing or chipping.

Roughness is usually assessed only qualitatively, by observing the substrate surface and by classifying it from very smooth to very rough. Eurocode 2 [2] indicates that, for shear at the interface between concrete cast at different times, "in the absence of more detailed information, surfaces may be classified as very smooth, smooth, rough or

\footnotetext{
* Corresponding author.

E-mail address: ejulio@dec.uc.pt (E.N.B.S. Júlio).
}

indented". ACI 318 [3] specifies two categories of roughness and BS 8110 [4] only considers the equipment that should be used to create the desired roughness. This type of roughness evaluation has obvious disadvantages due to the subjectiveness of results. To overcome this situation some attempts have been made. For instance, the International Concrete Repair Institute (ICRI), has defined nine standard profiles of increasing roughness in order to classify, by comparison with these, the roughness of a concrete surface.

The authors have decided to study if an alternative method can be used. The main objective was to explore the possibility of quantifying the surface roughness instead of classifying it in a qualitative way. This approach would have the clear advantage of results not being influenced by the observer.

\section{Roughness parameters}

Several parameters were adopted to quantify the surface roughness and are presented in the following paragraphs. 
These parameters may be considered individually or combined.

The average roughness, $R_{\mathrm{a}}$ (Fig. 1), is given by [5]:

$R_{\mathrm{a}}=\frac{1}{l_{\mathrm{m}}} \int_{0}^{l_{\mathrm{m}}}|y(x)| \mathrm{d} x$

where $l_{\mathrm{m}}$ is the evaluation length; and $y(x)$ is the profile height at position $x$.

The mean peak-to-valley height, $R_{z(\mathrm{DIN})}$ (Fig. 2), is given by [5]:

$R_{z(\mathrm{DIN})}=\frac{1}{5} \sum_{i=1}^{5} z_{i}$

where $z_{i}$ is the peak-to-valley height in each cut-off length.

The maximum peak-to-valley height, $R_{\max }$, is given by [5]:

$R_{\max }=\max \left\{z_{i}\right\}$

where $z_{i}$ is the peak-to-valley height.

The mean third highest peak-to-valley height, $R_{3 z}$, is given by $[5]$ :

$R_{3 z}=\frac{1}{5} \sum_{i=1}^{5} R_{3 z i}$

where $R_{3 z i}$ is the third highest peak-to-valley height.

The maximum third highest peak-to-valley height, $R_{3 z \max }$, is given by [5]:

$R_{3 z \max }=\max \left\{R_{3 z i}\right\}$

where $R_{3 z i}$ is the third highest peak-to-valley height.
The ten points height, $R_{z(\mathrm{ISO})}$, is given by [5]:

$R_{z(\mathrm{ISO})}=\frac{1}{5}\left(\sum_{i=1}^{5} p_{i}+\sum_{i=1}^{5} v_{i}\right)$

where $p_{i}$ is the peak height in each cut-off length; and $v_{i}$ is the valley depth in each cut-off length.

The total roughness height, $R_{y}$, is given by [5]:

$R_{y}=p_{\max }-v_{\max }$

where $p_{\max }$ is the maximum peak height; and $v_{\max }$ is the maximum valley depth.

The mean peak height, $R_{\mathrm{pm}}$, is given by [5]:

$R_{\mathrm{pm}}=\frac{1}{5} \sum_{i=1}^{5} p_{i}$

where $p_{i}$ is the peak height in each cut-off length.

The maximum peak height, $R_{\mathrm{p}}$, is given by [5]:

$R_{\mathrm{p}}=\max \left\{p_{i}\right\}$

where $p_{i}$ is the peak height.

The mean valley depth, $R_{\mathrm{vm}}$, is given by [5]:

$R_{\mathrm{vm}}=\frac{1}{5} \sum_{i=1}^{5} v_{i}$

where $v_{i}$ is the valley depth in each cut-off length.

The maximum valley depth, $R_{\mathrm{v}}$, is given by [5]:

$R_{\mathrm{v}}=\max \left\{v_{i}\right\}$

where $v_{i}$ is the valley depth.

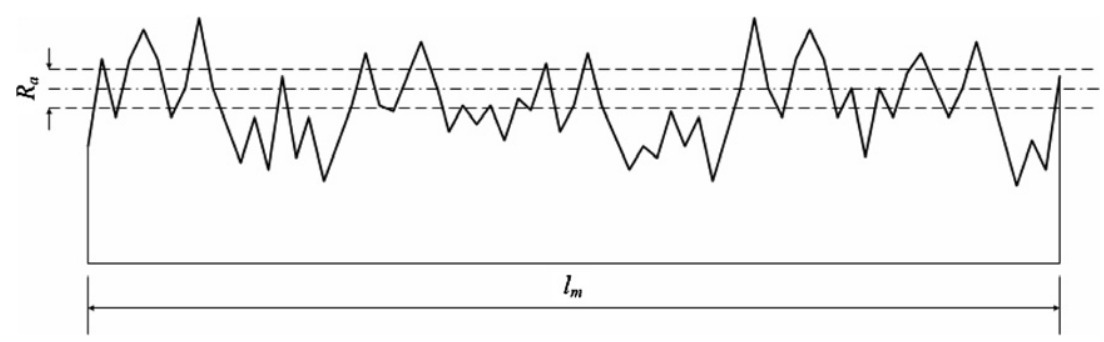

Fig. 1. Average roughness, $R_{\mathrm{a}}$

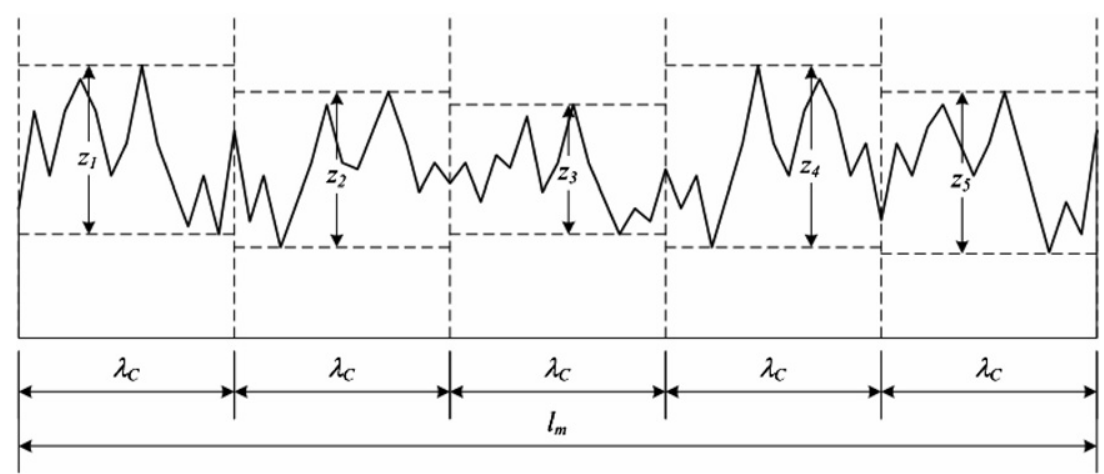

Fig. 2. Mean peak-to-valley height, $R_{z}$. 


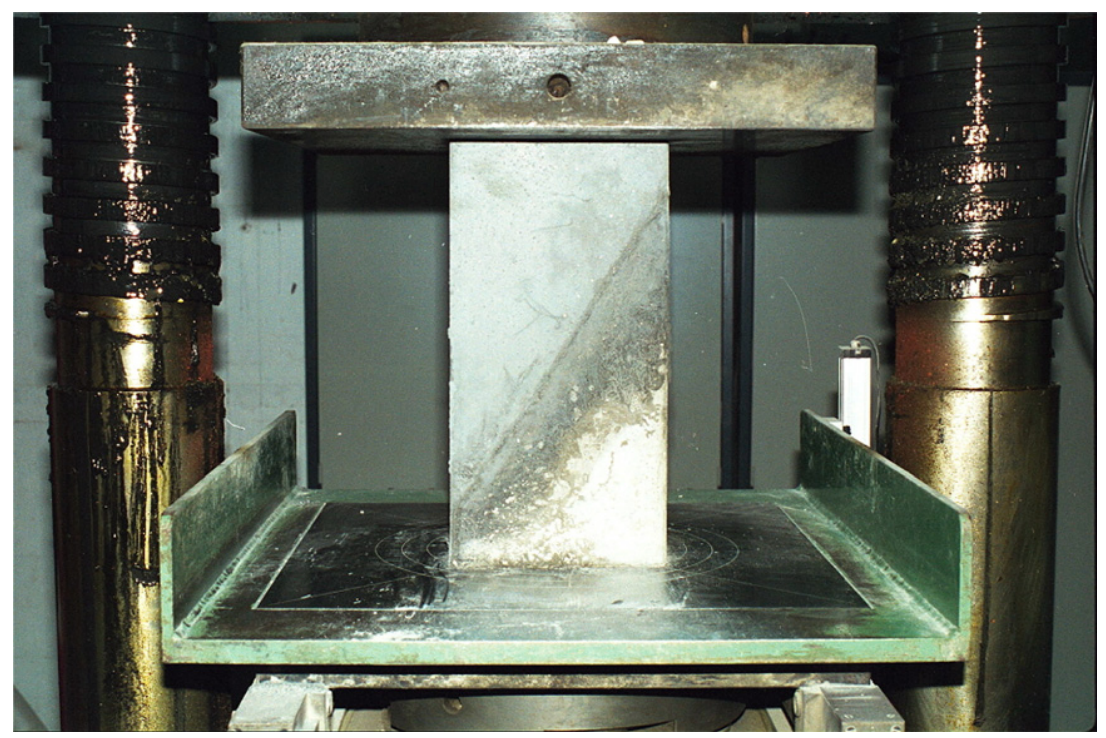

Fig. 3. Slant shear test.

The cut-off length, in this case, is equal to the evaluation length divided by 5 .

\section{Profile of the surface roughness}

The roughness parameters can only be determined from a profile of the surface roughness. To obtain this profile, several techniques are available.

Abu-Tair et al. [6] proposed a destructive technique that requires the extraction of a concrete specimen. First, a set of needles is placed over the concrete surface, self adjusting

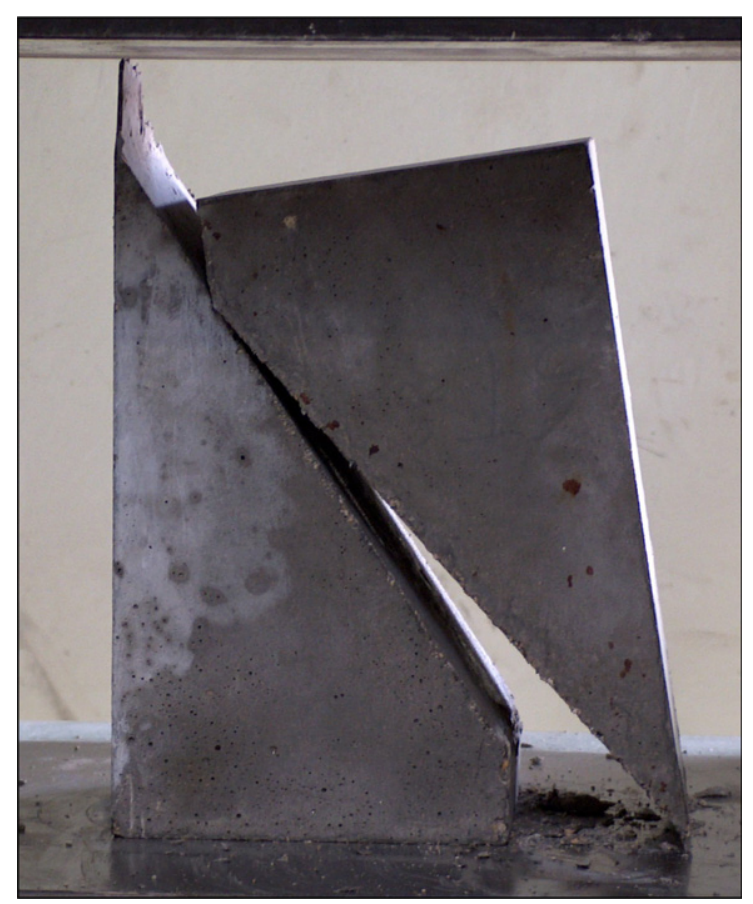

Fig. 4. Slant shear test adhesive failure. to this one, and fixed. Then, the concrete specimen is removed and the set of needles, that have the shape of the surface, is photographed against a high contrast surface. The obtained image is digitally treated and the roughness profile is assessed.

Issa et al. [7] proposed a modified version of the slitisland method, using dyed water instead of a filling material. In this method, the filling material is applied over

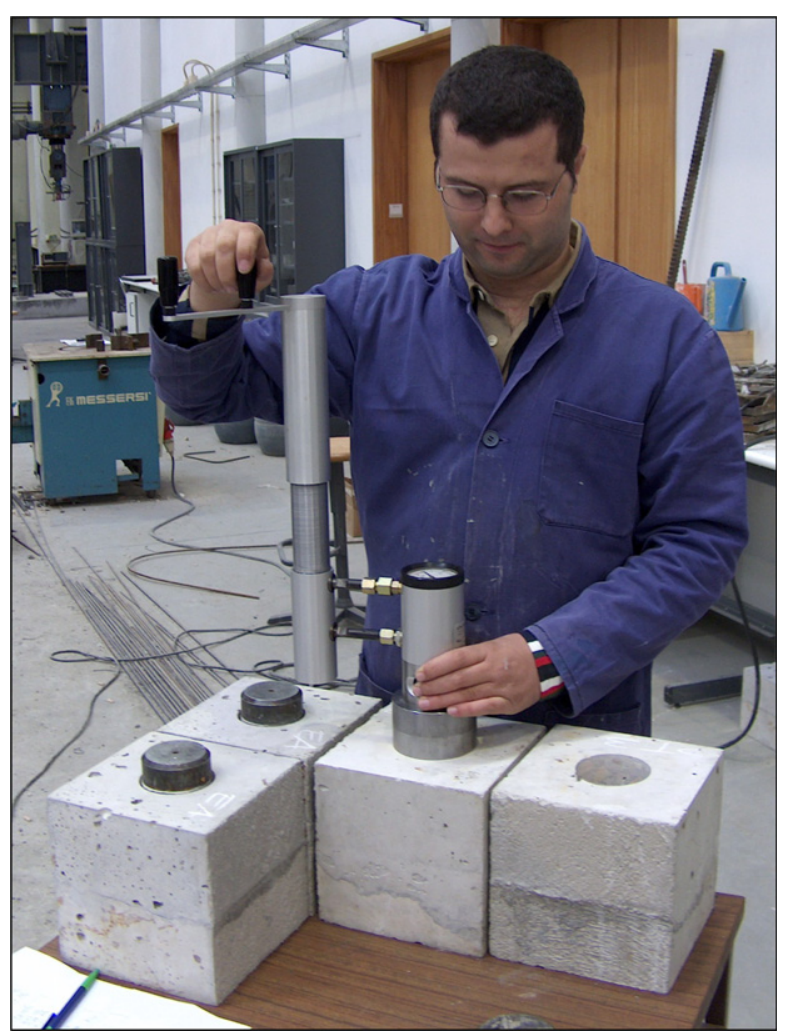

Fig. 5. Pull-off test. 
the surface and, after curing, is carefully polished, parallel to a reference plane. While the filling material is being removed, layer by layer, islands of the base material appear, growing and merging. For each layer, the contour line of each island is defined and a 3D model is computed. The fractal dimension is determined and correlated with the roughness of the surface.

Garbacz et al. [8] used a commercial testing device composed of a stylus, a conditioner/amplifier, a mechanical unit for advancement and a computer unit for data acquisition.

Maerz et al. $[9,10]$ used several techniques: laser striping, shadow profilometry and texture mapping. The first method uses a laser profiling line rather than a linear beam of light or shadow edge.

Optical methods, using laser equipment, present major advantages: this type of procedure is truly non-destructive, it is not sensitive to colour contrast between aggregate and

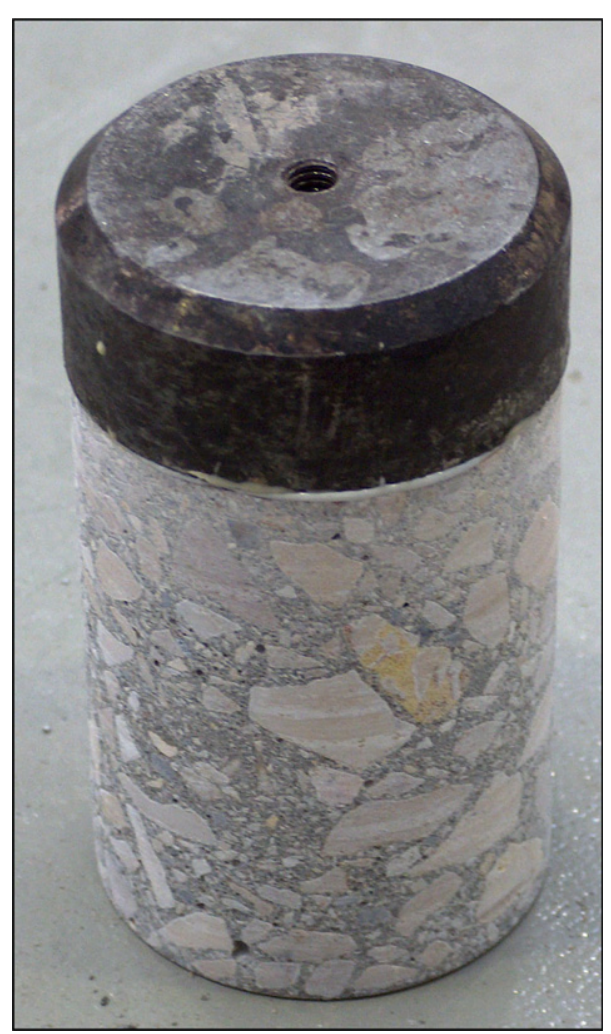

Fig. 6. Pull-off test adhesive failure. cement paste, and contact between equipment and surface is avoided. As a consequence, more accurate results are obtained.

\section{Experimental study}

The objective of this experimental study was to analyse if the surface roughness of the concrete substrate can be classified using roughness parameters and to verify if these parameters can be correlated with the bond strength of the interface.

Slant shear and pull-off tests were adopted to assess bond strength in shear and in tension, respectively. In the slant shear test, a concrete specimen is tested under compression, Fig. 3. The adopted geometry was a $0.20 \times 0.20 \times 0.40 \mathrm{~m}^{3}$ prism, with the interface at approximately $30^{\circ}$ to the vertical. The rupture mode of the specimen in this test may be monolithic or adhesive, Fig. 4. The pull-off test, Fig. 5, is a tensile test. A $0.20 \mathrm{~m}$ cube was adopted, with the interface at middle height. A core of $75 \mathrm{~mm}$ diameter was drilled into the added concrete until the substrate was reached and extending $15 \mathrm{~mm}$ beyond the interface into the substrate layer. A steel disc was bonded to the surface of the core, with an epoxy resin, and a tension force was applied. The failure mode in this test may

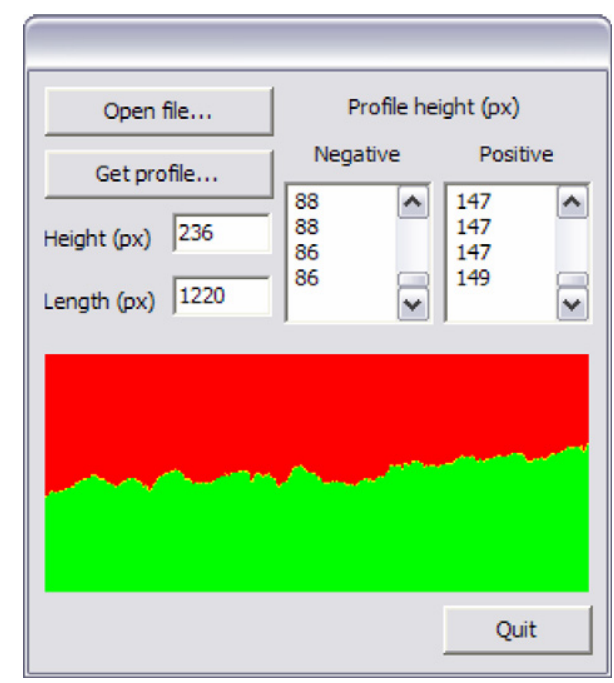

Fig. 8. Roughness profile coordinates.

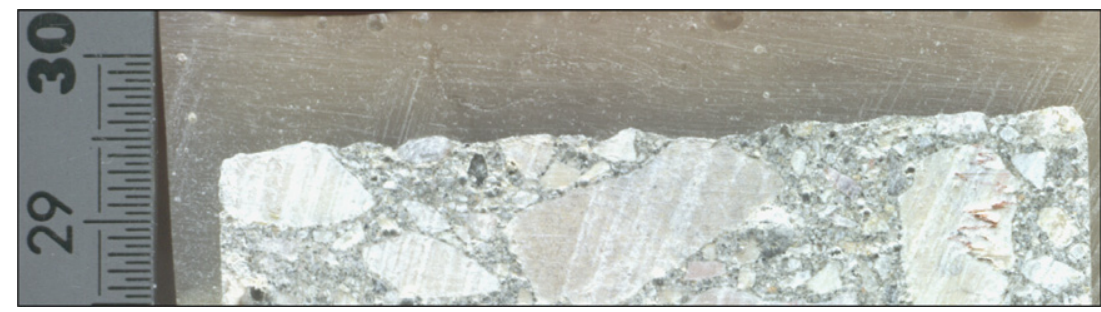

Fig. 7. Digital image from concrete specimen. 
occur at the interface, being adhesive, Fig. 6, or cohesive, or it may be a tensile rupture in one of the concrete layers.

Temperature and relative humidity in the laboratory were not controlled. All other parameters that could influence the bond strength were kept constant: concrete substrate mix; added concrete mix; and their ages. The average compressive strength of both substrate and added concretes was $50.40 \mathrm{MPa}$ and $46.22 \mathrm{MPa}$, respectively.

First, three sets of five slant shear half-specimens and five pull-off half-specimens were cast against steel formwork. Then, the specimens of each set were prepared with the same surface treatment. The following situations were considered: (1) smooth surface, specimens left as-cast against steel formwork; (2) slightly rough surface, specimens treated with wire-brushing, without exposing the aggregates; and (3) rough surface, specimens prepared with sand-blasting, exposing the aggregates.

Afterwards, to define the roughness profile of the substrate, samples were cut off from $0.20 \times 0.20 \times 0.10 \mathrm{~m}^{3}$ specimens, subjected to the same surface treatments as the specimens used in slant shear and pull-off tests. The extracted samples were subjected to a preparation procedure consisting on the following steps [11]:

(a) Cleaning of specimen surface with acetone to remove oils, grease, etc;

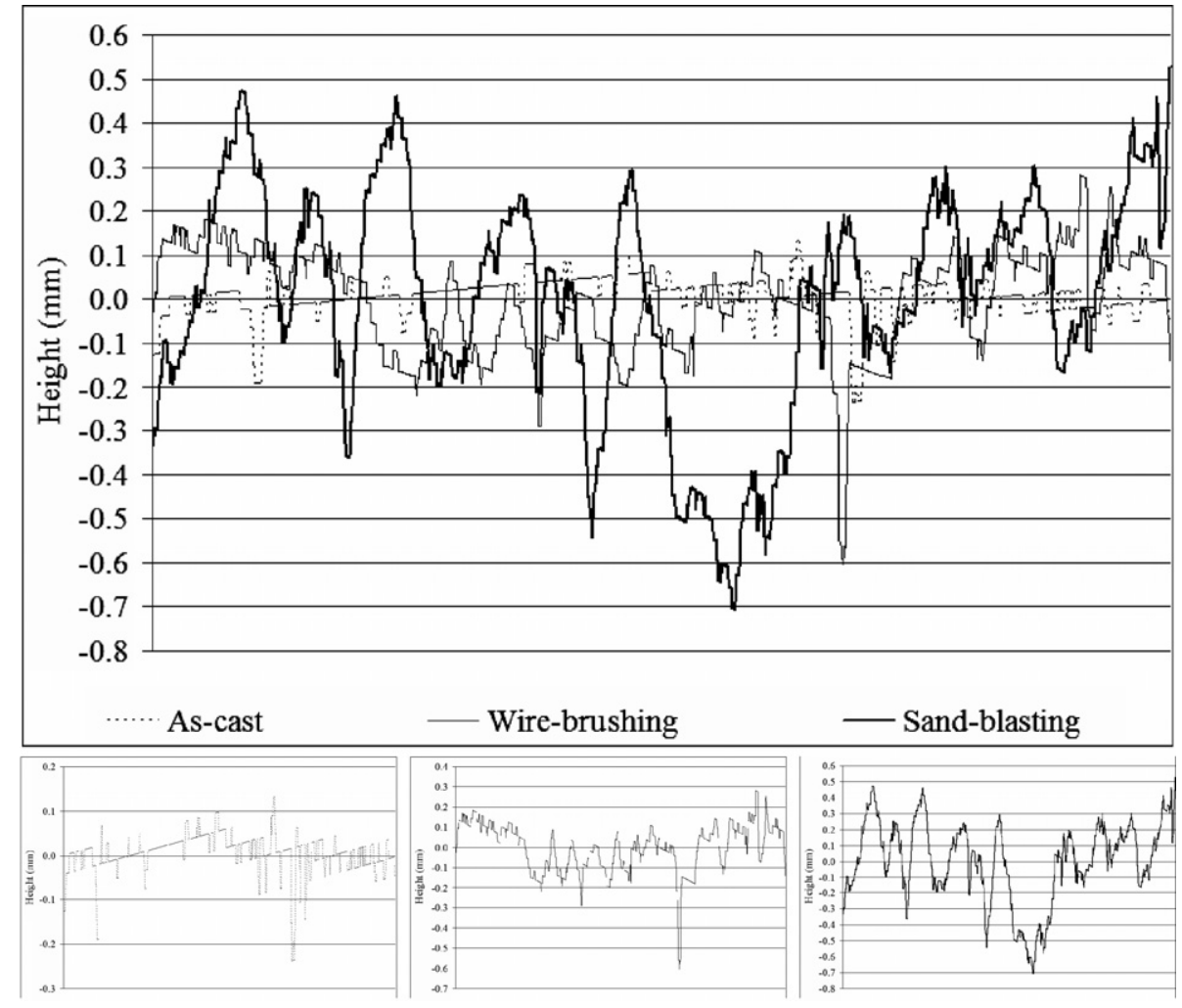

Fig. 9. Roughness profile comparison.

Table 1

Roughness parameters

Roughness parameter (mm)

Substrate treatment

Average roughness

Mean peak-to-valley height

Maximum peak-to-valley height

Mean third highest peak-to-valley height

Maximum third highest peak-to-valley height

Ten points height

Total roughness height

Mean peak height

Maximum peak height

Mean valley depth

\begin{tabular}{lll}
\hline As-cast & Wire-brushed & Sand-blasted \\
0.031 & 0.099 & 0.203 \\
0.213 & 0.403 & 0.797 \\
0.370 & 0.708 & 0.994 \\
0.118 & 0.252 & 0.628 \\
0.188 & 0.347 & 0.825 \\
0.293 & 0.605 & 1.088 \\
0.370 & 0.847 & 1.231 \\
0.083 & 0.160 & 0.401 \\
0.132 & 0.282 & 0.527 \\
0.130 & 0.243 & 0.396 \\
0.238 & 0.565 & 0.704
\end{tabular}

Maximum valley depth

$\begin{array}{ll}R_{\mathrm{a}} & 0.031 \\ R_{z(\mathrm{DIN})} & 0.213 \\ R_{\max } & 0.370 \\ R_{3 z} & 0.118 \\ R_{3 z \max } & 0.188 \\ R_{z(\mathrm{ISO})} & 0.293 \\ R_{y} & 0.370 \\ R_{\mathrm{pm}} & 0.083 \\ R_{\mathrm{p}} & 0.132 \\ R_{\mathrm{vm}} & 0.130 \\ R_{\mathrm{v}} & 0.238\end{array}$




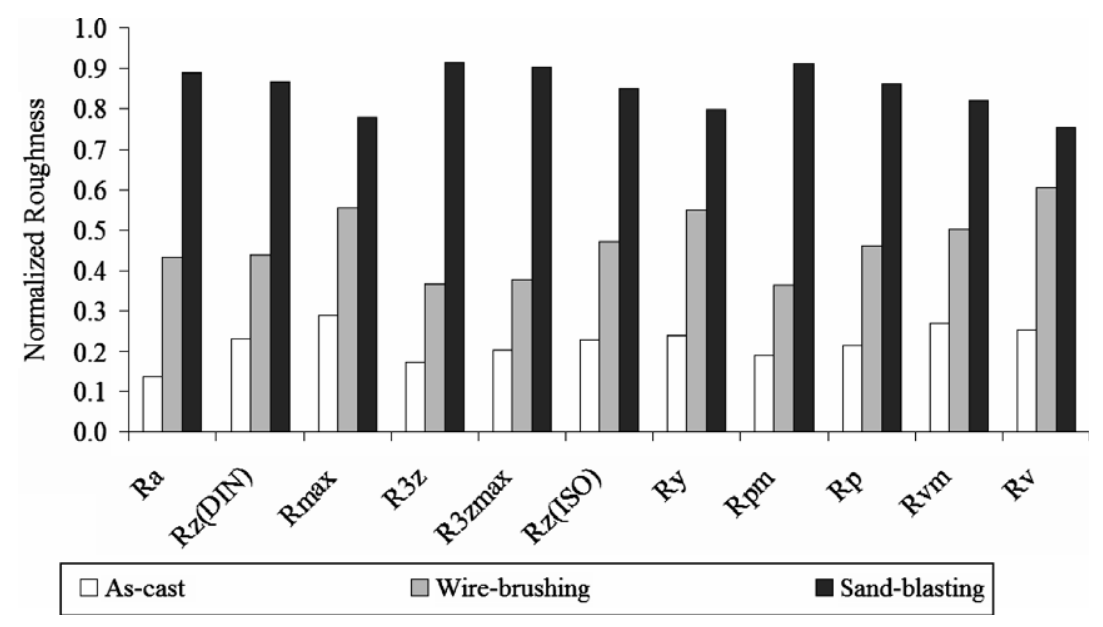

Fig. 10. Normalized roughness parameters.

(b) Application of an epoxy resin over the specimen surface;

(c) Sawing on a plane perpendicular to the surface and polishing of the specimen; (d) Creation of a digital image using an auxiliary metric scale, Fig. 7;

(e) Treatment of the obtained digital image to identify the parts corresponding to resin and concrete;

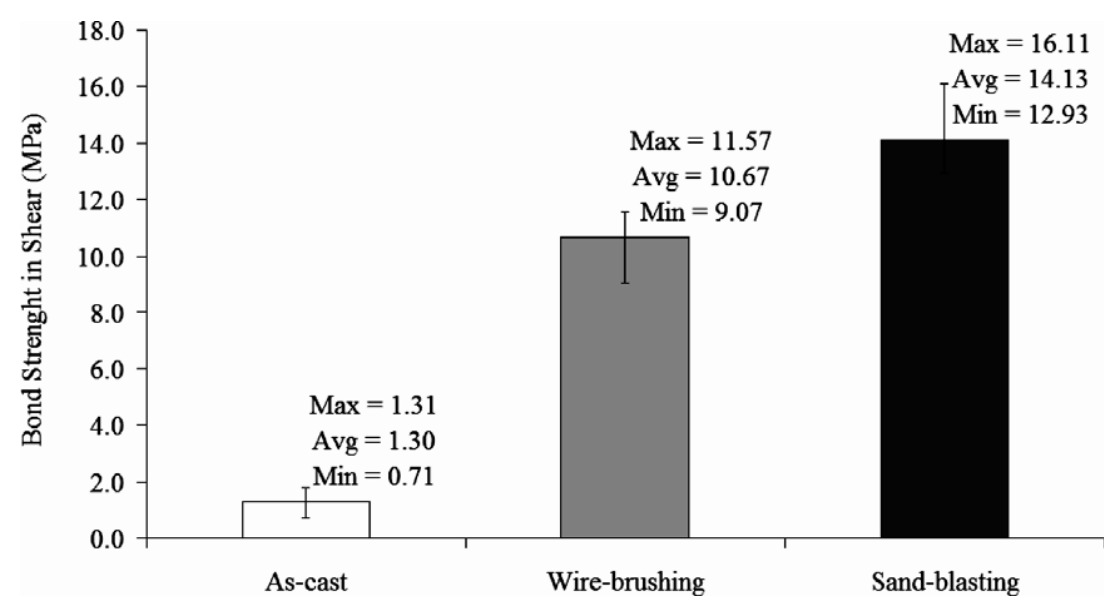

Fig. 11. Slant shear test results.

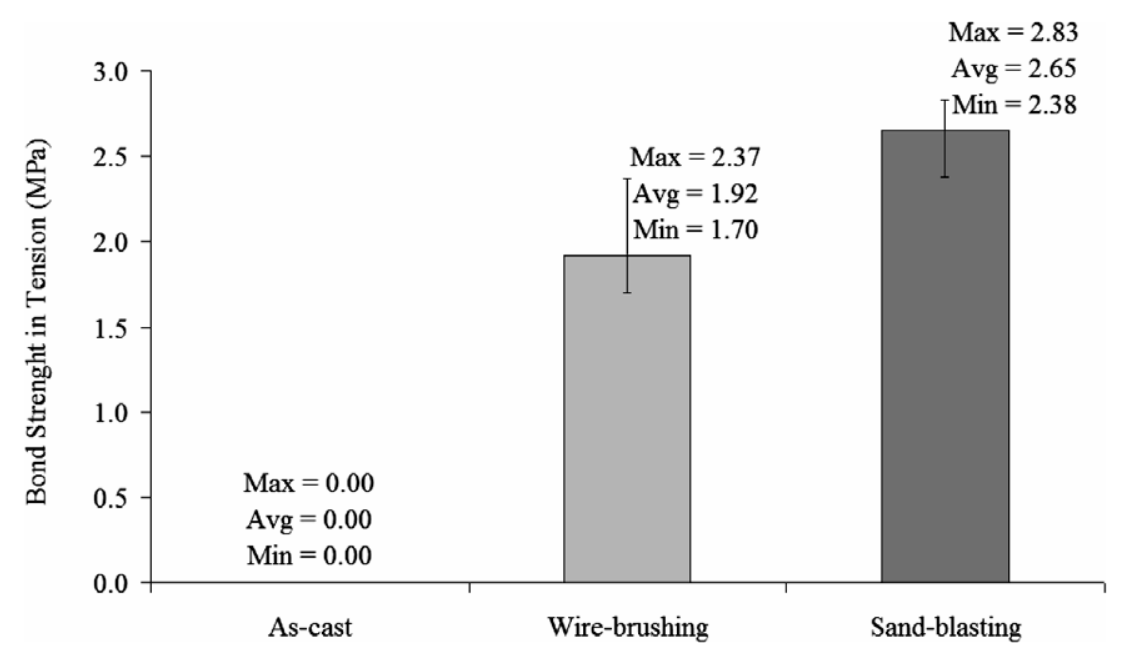

Fig. 12. Pull-off test results. 
Table 2

Normalized roughness parameters

Normalized roughness parameter $(\mathrm{mm})$ Substrate treatment

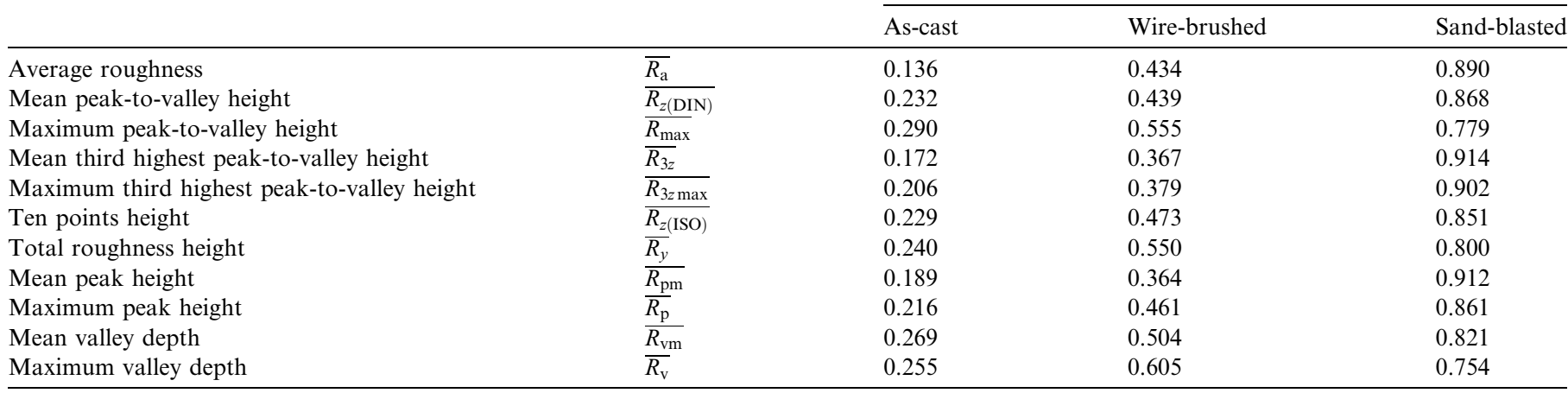

(f) Determination of the coordinates of the roughness profile, Fig. 8;

(g) Transformation of coordinates to remove the effect of the profile orientation.

In Fig. 9 the profiles obtained with the three considered techniques of surface preparation are presented superimposed. The evaluation length should be at least 2.5-3.0 times the maximum roughness depth to capture two consecutive peaks and valleys. Since some of the roughness parameters require the division of the evaluation length in five equal parts and taking into account an estimated maximum peak-to-valley height of approximately $1 \mathrm{~mm}$, the total evaluation length should be, at least, 12.5$15.0 \mathrm{~mm}$. Given that the adopted evaluation length was of approximately $50 \mathrm{~mm}$, it was adequate to characterize the concrete substrate roughness. The mean line of the profiles was placed at zero to allow a direct comparison. Subsequently, eleven of the most used roughness parameters were determined for each profile (Table 1) and were normalized (Table 2) to allow a better analysis of results, Fig. 10, since the values obtained for each roughness parameter are in different scales. The normalized parameters were obtained dividing the original parameters by the square root of the sum of squares of the measured values.

Results obtained, in terms of profiles, and corresponding roughness parameters computed, are identical to other published studies. For instance, Garbacz et al. [8] obtained, for a sand-blasted substrate surface, a value of the peakto-valley height that did not exceed $1 \mathrm{~mm}$. In this study, the mean peak-to-valley heights are $0.213 \mathrm{~mm}, 0.403 \mathrm{~mm}$ and $0.797 \mathrm{~mm}$, and the maximum peak-to-valley heights are $0.307 \mathrm{~mm}, 0.708 \mathrm{~mm}$ and $0.994 \mathrm{~mm}$ for the three considered situations, without treatment, wire-brushed surface and sand-blasted surface, respectively.

After 84 days, the first halves of the specimens were cleaned and the second halves were cast, parallel to the interface surface; and 28 days later slant shear and pulloff tests were performed. The results obtained are presented in Figs. 11 and 12. Results of the pull-off test of situation "left as-cast against steel formwork" are not presented
Table 3

Coefficient of correlation

Roughness parameter

Coefficient of correlation ( $R$-squared)

\begin{tabular}{|c|c|c|c|}
\hline & & \\
\hline & & Shear & Tensior \\
\hline Average roughness & $R_{\mathrm{a}}$ & 0.9283 & 0.9306 \\
\hline Mean peak-to-valley height & $R_{z(\mathrm{DIN})}$ & 0.8966 & 0.8994 \\
\hline Maximum peak-to-valley height & $R_{\max }$ & 0.9776 & 0.9789 \\
\hline Mean third highest peak-to-valley height & $R_{3 z}$ & 0.8642 & 0.8673 \\
\hline Maximum third highest peak-to-valley height & $R_{3 z \max }$ & 0.8570 & 0.8602 \\
\hline Ten points height & $R_{z(\mathrm{ISO})}$ & 0.9271 & 0.9295 \\
\hline Total roughness height & $R_{y}$ & 0.9805 & 0.9817 \\
\hline Mean peak height & $R_{\mathrm{pm}}$ & 0.8535 & 0.8567 \\
\hline Maximum peak height & $R_{\mathrm{p}}$ & 0.9219 & 0.9243 \\
\hline Mean valley depth & $R_{\mathrm{vm}}$ & 0.9401 & 0.9423 \\
\hline Maximum valley depth & $R_{\mathrm{V}}$ & 0.9995 & 0.9997 \\
\hline
\end{tabular}

because de-bonding occurred for each of the five specimens of this situation, while drilling the core.

Finally, the roughness parameters, determined for the substrate surface left-as-cast, wire-brushed and sandblasted, were correlated with the bond strength in shear and in tension, assuming a linear relationship, being the corresponding coefficients of correlation presented in Table 3 .

\section{Conclusions}

The technique adopted to obtain the roughness profile gave good quality results. Nevertheless, for smooth surfaces, more accurate equipment is needed to obtain the digital image of the profile, to avoid difficulties in the identification of the latter. An optical procedure, like laser profilometry, would be probably the most adequate technique and it would also present the advantage of being non-destructive.

It is possible to adopt roughness parameters and correlate these with bond strength in shear and in tension, experimentally determined with slant shear and pull-off tests. Furthermore, assuming a linear relationship, a good coefficient of correlation was obtained. Consequently, it seems adequate to adopt in design codes a quantitative method 
for assessing shear at the interface between concrete cast at different times, instead of the current qualitative process.

Finally, it is advisable to use roughness parameters like maximum peak-to-valley height, total roughness height or maximum valley depth, since these correspond to the highest coefficient of correlation obtained.

\section{References}

[1] Júlio ENBS, Branco FAB, Silva VD. Concrete-to-concrete bond strength. Influence of the roughness of the substrate surface. Constr Build Mater 2004;18:675-81.

[2] prEN 1992-1-1, Eurocode 2: Design of concrete structures - Part 1.1: General rules and rules for buildings, April 2003.

[3] ACI 318, ACI manual of concrete practice, Part 3 - 1994, Use of concrete in buildings - design, specifications, and related topics, American Concrete Institute, 1996.

[4] BS 8110, Structural use of concrete, british standards institution, 2 Park Street, London W1A 2BS, 1985.
[5] Mummery L. Surface texture analysis - the handbook, Hommelwerke GmbH, Thyssen, 2000.

[6] Abu-Tair AI, Lavery D, Nadjai A, Rigden SR, Ahmed TMA. A new method for evaluating the surface roughness of concrete cut for repair or strengthening. Constr Build Mater 2000;24: $171-6$.

[7] Issa MA, Islam MS, Chudovsky A. Fractal dimension - a measure of fracture roughness and toughness of concrete. Eng Fract Mech 2003;70:125-37.

[8] Garbacz A, Górka M, Courard L. On the effect of concrete surface treatment on adhesion in repair systems. Mag Concrete Res 2005;57:49-60.

[9] Maerz N. Feasibility study - concrete roughness measuring device. Center for Infrastructure Engineering Studies, University of Missouri-Rolla, 1999.

[10] Maerz N, Nanni A, Myers J, Galecki G. Laser profilometry for concrete substrate characterization prior to FRP laminate application. Concrete Repair Bull 2001:4-8.

[11] Santos PMD. Influence of the surface roughness of the interface concrete/concrete in its longitudinal shear resistance, MSc Thesis, University of Coimbra, 2005. [in Portuguese]. 